\title{
Embroidery Technology and Its Application in Fashion Design
}

\author{
Zhen Xuan \\ Jiang xi Institute of Fashion Technology \\ Jiang xi, Nanchang, China 330201
}

\begin{abstract}
In thousands of years of Chinese history, we have rich and colorful art and culture. The art of embroidery is a representative craftsmanship. Early in the Spring and Autumn Period, there were large-scale handmade embroidery products. Traditional embroidery crafts are all handmade embroidery, and all works are delicate. With the continuous deepening of industrial production, handmade embroidery is gradually replaced by embroidery equipment, and a lot of elements of times in form, color and other aspects are added into it. The embroidery begins to enter into the daily life of the masses, and is widely used in the fashion field. This paper mainly has discussed the related issues of the application of embroidery technology in fashion design.
\end{abstract}

Keywords—embroidery technology; fashion design; handmade embroidery

\section{INTRODUCTION}

As early as in ancient times, embroidery technology has been widely used in the fashion field. Traditional minority clothing has contained different forms of embroidery art. Embroidery is a traditional folk craft. Combined with rich texture and imag ination, forms a variety of embroideries. On the modern society of multi-culture, more and more Western cultures enter into our country, and they have produced a great impact on traditional culture and technological production. The embroidery technology also need to conform to the development trend of the times, and add more modern elements on the basis of traditional technology to meet the aesthetic needs of modern people.

\section{OVER VIEW OF EMBROIDERY TECHNOLOGY}

\section{A. The Development of Embroidery Technology}

The origin of embroidery in China can be traced back to the Spring and Autumn and the Warring States Period. It has experienced the rise and fall of a number of historical dynasties. Gradually the embroidery art with different historical characteristics has been formed. In modern society, the standard industrial production technology gradually replaces the traditional artis an craftsmanship. But embroidery art still is widely used in various fields, and has assumed an important responsibility in the spread of the history and culture. It has become an important part in the promotion of the development of national culture. The embroidery technology uses embroidery needle as operating tool. On fabric, draw patterns according to predesign, use silk thread of different color and size, and form many beautiful pictures. From the beginning of its birth, the embroidery technology has been closely linked with the fashion field. The embroidery pattern and used silk threads were important elements to weight the quality of clothing at a time. In different historical periods, the embroidery technology has been widely used in the fashion design field. After the art processing on existing clothing fabric, form different colors and patterns with embroidery, and thus meet the aesthetic pursuit of designers. With the continuous development of modern society and the acceleration of industrial production, more and more embroidery equip ment is used in the production of embroidery products. The computer technology can be used to produce different forms of embroidery. But the traditional embroidery technology, with handmade embroidery as representative, is still an important pursuit of designers. Handmade embroidery not only has a unique skill and craftsmanship, and also contains a rich personal emotion and spiritual sustenance, which makes the embroidery crafts more appealing.

\section{B. Types of Embroidery}

In different historical periods, the embroidery technology has different characteristics of the times, and has been endowed with different historical and cultural characteristics. The embroidery classification according to regions is the main basis to classify embroidery technology in modern society. In past time, people classified embroidery mainly according to regional characteristics, such as, $\mathrm{Su}$ embroidery, Shu embroidery and Xiang embroidery. In the development of embroidery art, there were different culture conflicts and integration phenomena, so that the embroidery art is endowed with the integrated cultural characteristics. The embroidery, with regional characteristics as classification basis, has obvious differences in skill and expression form. For example, $\mathrm{Su}$ embroidery has a high requirement on craftsmanship and skill, and it usually has a strong appealing force and gives clothing with fresh national cultural characteristics. In addition to the region classification method, it also can be classified according its stitching method, appearance of fin ished product, embroidery materials and other elements. All types of classification can reflect the notable characteristics of the embroidery in art, culture and customs. It has laid a solid foundation for the development of embroidery art in modern society. 


\section{THE APPLICAT ION PRINCIPLES OF EMBROIDERY TECHNOLOGY IN FASHION DESIGN}

Under the environment of modern society, people's material living standards constantly improve, and people's pursuit for spiritual and cultural life is becoming stronger and stronger. As a traditional art, the embroidery is applied to fashion design increasingly. On the one hand, it can meet the diversified and personalized consumption demand of consumers. On the other hand, it can endow fashion works with more spiritual connotations. The application of embroidery technology in fashion design shall follow the following main principles.

\section{A. Layout, in Line with the Design Requirements of Clothing}

The application of embroidery in fashion design is more of a decorative modeling, so it should be consistent with the whole modeling of the clothing, including clothing style, embroidery patterns, techniques and threads. The application of separate element should be harmony with the whole form, so as to fully show the decoration function of embroidery in fashion design. In addition, we should make continuous innovation on embroidery technology and forms, and keep it consistent with fabric and patterns of clothing in order to reach a desired result.

\section{B. Embroidery Patterns, Consistent with Clothing Style}

The patterns of embroidery are very rich, and they are connected with painting art. It is able to complete the embroidery process with complete pattern planning. There are many styles, such as, traditional style, modern style and abstract style. Different embroidery patterns could produce different visual and spiritual feel, and they have a great impact on the entire appearance of clothing. Therefore, if we use the embroidery technology in fashion design, we should consider the entire pattern style of the clothing, and keep the embroidery pattern consistent with the entire style of the clothing and form a harmony whole, thus to set off the theme of the clothing.

\section{Materials, Matching with Clothing Fabrics}

All kinds of threads and techniques used in embroidery give embroidery with different forms and fabric feel, and make people produce different feelings. So, we should ensure that the embroidery materials match with clothing fabrics. We should select appropriate embroidery materials according to the requirements of clothing fabrics, so as to add the finishing touch in the clothing.

\section{Embroidery Colors, Matching with Clothing}

The fashion field has a high requirement on color match. In the embroidery art, we should also grasp basic methods of color match. We can use it according to the method of anagogic colors, contrast colors, and complementary colors. We can effectively coordinate embroidery with clothing, so as to get a non-monotonous and uncomplicated color match for fashion design. It enables to highlight the characteristics of embroidery in entire fashion design, and will not overwhelmingly affect the coordination of clothing.

\section{THE SPECIFIC APPLICATION OF EMBROIDERY TECHNOLOGY IN FASHION DESIGN}

We have a long history in the application of embroidery technology in fashion field. Each of our national minorities has used different embroidery technologies and patterns on their clothing. Many embroidery patterns are endowed with the cultural connotation of minorities. They represent peace, luck and other good wishes. The application of embroidery technology in modern fashion design can be summarized as the following two aspects.

\section{A. The Application of Embroidery Art in Traditional Fashion Design}

1) The application of embroidery technology in minority fashion design: The clothing of ethnic minorities in our country is bright in color and different in forms. The clothing of many minorities has used embroidery technology, such as, Miao nationality, Yi nationality, Bai nationality and Mongolia nationality. In minorities, Miao nationality has relatively mature embroidery technology and their application scope is large. The patterns include fish, bird, dragon and flowers, and these embroidery patterns are attractive and vivid. If we combine them with modern elements, we can get characteristic modern clothing. In addition to Miao nationality, minorities in Guangxi also are good at using embroidery technology. They often dye the original cloth and cut it, and then take it as base fabric to embroider. This method increases the thickness of cloth, and protects easily worn-out part without losing its beauty.

2) The application of embroidery in cheongsam design: Cheongsam is China's most representative traditional clothing. In cheongsam design, we often use colored embroidery. Use different colors of silk threads to embroider rich and colorful patterns through overlapping and juxtaposition, and form smooth wash-painting-like lines to add the unique taste of cheongsam. Modern people are more sophisticated in the selection of fabric for cheongsam. They cut the dress according to one's figure in order to make it more suitable and fully show the elegance of Oriental women. The patterns used in cheongsam mainly are plum blossom and peony, as well as flower patterns in form of wash painting technique, which are elegant and beautiful, and adds a touch of culture. In cheongsam design, Su embroidery cheongsam is the representative. It selects high-quality silk fabric, and is decorated with Chinese rose, peony, orchid and other elegant patterns. Embroider patterns before breast, on collar or cuffs. Their technique is very superior. In order to meet consumer's aesthetic pursuit, modern cheongsam may be decorated with rhinestones, pearls and so on in appropriate position, to add a touch of elegance.

\section{B. The Application of Embroidery Art in Modern Fashion Design}

1) The application of embroidery in branded fashion design: We can see the embroidery technology in many brands of clothing. They combine modern fashion design with 
traditional embroidery craft, which can bring a new selling point to merchants and attract a lot of consumers. Some clothes perfectly combine Western simple cutting art and Oriental embroidery art, which gives traditional culture with more modern elements. It also provides a wide channel for the development of traditional culture. In fashion design, the embroidery craft is often used on collar, cuffs, trouser legs and chest. It satisfies the pursuit of modern people in fashion style, and endows clothing with more Oriental cultural flavor, and thus to gain the preference of consumers. Especially in design of women's dress, use hollowed decorative effect on thin cotton cloth or textile fabrics, forming a perspective effect. This art technique is very popular among many young women. In addition to some ordinary brands, many sports brands also are partial to the Oriental embroidery. The logos of some brands use embroidery craft, and they put it in a striking position to avoid monotonous ness and attract children and make children's clothing more characteristic.

2) The application of embroidery in high-end custommade clothing: We can see the application of embroidery art in high-end custom-made clothing and well-known brand fashion conference. The art process of designers can increase the elegance of formal dress. And the clothing can be made according to personal needs to highlight the uniqueness of the clothes. The embroidery art has contained rich Chinese flavors. Golden dragon and colorful phoenix can be the outstanding patterns on fashion stage. By combing the embroidery art with international high-end fashion brands, we can get more market elements for Chinese embroidery and gradually lead Chinese traditional art to the international stage, and fully show the beauty of Chinese fashion. Today, Chinese embroidery is very common in high-end custom-made clothes. In the journey of Dior Designer John Gary Galliano to china, he found Chinese embroidery. He regarded it as a treasure. In the women's dress of Dior, he largely used Chinese embroidery as decorative element. In addition, we can also see the beautiful shadow of Chinese embroidery on the clothes of Prada, D\&G and other well-known brands. It has fully reflected that the position of Chinese embroidery is constantly upgrading in the international fashion stage.

\section{CONCLUSION}

In summary, embroidery is a traditional art of Chinese nation. After years of development, the embroidery art has been formed with different characteristics in different historical periods and regions. In the modern fashion design field, we have a large space for the application of embroidery art. Designers can use different styles of embroidery art according to the styles of fashion design, and integrate traditional embroidery art with modern aes thetic characteristics to meet the pursuit of modern people for fashion art. With the continuous development and process of society, the embroidery art has showed a diversified development trend, and it gradually becomes the representative element to lead the fashion market trend. It has endowed Chinese fashion design with rich and abundant traditional cultural connotations.

\section{REFERENCES}

[1] Chen Lingyun. Application of Embroidery Technology in Fashion. Journal of Luohe Vocational Technology College, Jan. 15, 2013.

[2] Guo Li. Application of Traditional Embroidery Technology in Modern Fashion Design. Jiangsu T extile, Aug. 20, 2014.

[3] Wei Yulong. Innovative Application of Traditional Embroidery in Modern Fashion Design. Wool Spinning Technology, Jul. 5, 2014.

[4] Zhang Haijun. Application of Embroidery Technology in Fashion Design. Light T extile Industry and Technology. Dec. 25, 2014.

[5] Xu Qiang, Gan Yingjin. Application of Embroidery in Fashion Design. International Textile Leader, Sept. 15, 2007. 